\title{
XIX INTERNATIONAL SEMINAR ON ION-ATOM COLLISIONS - XIX ISIAC
}

This special issue of the Brazilian Journal of Physics contains the proceedings of the XIX International Seminar on Ion-Atom Collisions (XIX ISIAC), which was held in Rio de Janeiro, Brazil, on July 28-29, 2005. More than sixty participants, including graduate students, from fifteen countries, attended the XIX ISIAC, which consisted of 26 oral presentations and more than thirty posters.

These proceedings include some of the works which were presented during the seminar and document the illuminating discussions in the very pleasant atmosphere of the Planetarium of Rio de Janeiro.

We would like to thank all those who contributed to the success of this seminar: the chairpersons, the invited speakers, the participants, the staff of the Planetarium, who did every possible effort to make us feel at home, in particular the President of the Planetarium Foundation, Dra. Carmen Pizarro, and its Astronomy Director, Dr. Ormis Rossi, and the institutions which provided financial support (FAPERJ, CNPq, Fundação José Bonifácio). Last, but not least, we would like to express our gratitude to our colleagues of the Local Organizing Committee, Profs. Heloisa M. Boechart-Roberty, Luiz Felipe de Souza Coelho, and Antonio Carlos F. dos Santos, from the Federal University of Rio de Janeiro.

We would like also to thank all the authors who contributed with papers to this issue and the referees who helped us in the effort to improve the quality of the editorial work. We are especially grateful to the Chief Editor of the Brazilian Journal of Physics, Prof. Silvio R. A. Salinas, for accepting the publication of these proceedings, and to Ms. Neusa Martin of the Brazilian Physical Society for her invaluable help with the final editing process.

Rio de Janeiro, March 2006

Eduardo Chaves Montenegro and Geraldo Monteiro Sigaud Guest Editors 